\title{
Ganoderma lucidum Methanolic Extraction as a Potent Phytoconstituent: Characterization, in-vitro Antimicrobial and Cytotoxic Activity
}

\section{Seyyed Mojtaba Mousavi}

National Taiwan University of Science and Technology

Seyyed Alireza Hashemi

University of British Columbia

Ahmad Gholami ( $\square$ Gholami@sums.ac.ir)

Shiraz University of Medical Sciences

Navid Omidifar

Shiraz University of Medical Sciences

Wei-Hung Chiang

National Taiwan University of Science and Technology

Vijayakameswara Rao Neralla

National Taiwan University of Science and Technology

khadije Yousefi

Shiraz University of Medical Sciences

Mansoureh Shokripour

Shiraz University of Medical Sciences

\section{Research Article}

Keywords: Ganoderma lucidum, antibacterial, anticancer, breast cancer, blood cancer, Antibacterial activity

Posted Date: February 14th, 2022

DOI: https://doi.org/10.21203/rs.3.rs-1325112/v1

License: (c) (i) This work is licensed under a Creative Commons Attribution 4.0 International License. Read Full License 


\section{Abstract}

Background: Ganoderma lucidum has attracted tremendous attention due to its exceptional antimicrobial and anticancer properties that can be delicately tuned by controlling the initial extraction content and concentration. In the present experiment, we detailed the characterization, antimicrobial, and cytotoxic performance of Ganoderma lucidum as a potential multi-functional therapeutic agent.

Methods: In this study, we used FTIR, XRD, FESEM, EDX, and HPLC techniques to evaluate the samples, which were then followed by disc diffusion and microdilution broth methods to test its antibacterial effects against four Gram-positive and Gram-negative bacterial strains, Enterococcus faecalis, Staphylococcus aureus, Escherichia coli, and Pseudomonas aeruginosa. MTT assay was applied to determine the cytotoxic activity of this natural product against MCF-7 and K562 cancer cell lines.

Results: The results revealed that the inhibitory effects of this product had higher antibacterial activity against E. coli and Pseudomonas aeruginosa. The IC50 values of 0.5 and $0.75 \mathrm{mg} / \mathrm{mL}$ were obtained for MCF-7 and K-562 cancer cell lines, which confirmed the higher anticancer activity of the GLME against breast cancer cells compared to blood cancer cells.

Conclusions: Hence, these data provide pioneer insights into the therapeutic usage of Ganoderma lucidum for treating breast and blood cancers. This work is motivated by research studies looking for pharmacological products to address chronic and acute diseases, where further resources and studies are required to explore such products' adverse effects and toxicity.

\section{Background}

Natural products or herbal medicines maybe promising alternatives or supplement for chemotherapy and antibiotic therapy [1, 2]. Herbal medicines have extraordinary properties like high antibacterial, antioxidant, and anticancer activities [3, 4]. For thousands of years, Ganoderma lucidum (GL) has been used as a major source of pharmacologically active constituents in Chinese and traditional Japanese medicine. It has piqued the attention of researchers and scientists with its numerous medicinal and pharmacological uses since it contains significant pharmacologically active compounds [5-7]. Proteins, sugars, flavonoids, vitamins, minerals, triterpenes, and polysaccharides are among the biologically active compounds found in extractions of GL [8]. The presence of polysaccharides and triterpenoids in GL's structure has numerous pharmacological features. Thence, many experiments have been accomplished to investigate the performance of this natural product against different types of cancer like prostate cancer [9], lung cancer [10], colon cancer [11], and cervical cancer [12]. Also, GL's other pharmacological characteristics such as anti-inflammatory [13], hypoglycaemic [14], hypocholesterolemic [15], antioxidant activity [16], cardio-protective, hepato-protective, and anti-allergic activity, have been evaluated by researchers [5].

This research was planned and carried out in two parts to determine the characterization of GL methanolic extract (GLME) and investigate this natural product's antibacterial and cytotoxic activity. In 
the first part, to enhance GLME's properties, sample extraction was done via the standard method. The second portion of this study's antibacterial studies followed the Clinical and Laboratory Standards Institute (CLSI) recommendations. The disc diffusion assay was used to test GLME's antibacterial tolerance against Staphylococcus aureus, E. coli, Enterococcus faecalis, and Pseudomonas aeruginosa. The microdilution broth approach was then used to determine the minimum inhibitory concentrations (MICs) and minimum bactericidal concentrations (MBCs) of this substance, with both bactericidal and bacteriostatic effects defined. In the final section of this investigation, the cytotoxic activity of GLME against human breast cancer cells and human blood cancer cells was assessed through MTT assay.

\section{Materials And Methods}

\subsection{Sample extraction and preparation}

Pure dried $G L$ was purchased from a traditional market in Shiraz, Iran. The dried $G L$ was grounded to form a fine powder, and then its essence was extracted by pouring it with methanol at room temperature. In this regard, $2.5 \mathrm{~g}$ of dried $G L$ was first blended with $100 \mathrm{~mL}$ of methanol and then shook for $24 \mathrm{~h}$ at 125 $\mathrm{rpm}$. In the next step, the mixture was filtered using filter paper and placed in an oven at $60^{\circ} \mathrm{C}$ for $12 \mathrm{~h}$. After that, $3 \mathrm{mg}$ of the final extracted essence was dissolved in $\mathrm{MeOH}$ as the stock solution for biological tests.

\subsection{Characterization}

Different analyses were carried out to test the properties of GLME. FTIR spectroscopy with $\mathrm{KBr}$ tablets (Bruker model Tensor II) and X-ray diffraction (XRD) (Panalytical model X'Pert Pro, Almelo, Netherlands) was used to explore its crystallinity. The morphology of GLME (Tescan model S Max detector, Brno, Czech Republic) was studied using a field emission-scanning electron microscope (FE-SEM, Tescan model Mira III, Brno, Czech Republic) and energy dispersive spectroscopy (EDAX). An Azura HPLC device (Knauer, Berlin, Germany) fitted with a quaternary gradient pump unit and a UV-vis detector (190-700 nm) were used to study the contents of monosaccharides and disaccharides from GLME. The detector's wavelength was set to 250 nanometers. The components were separated by a Knauer C18 column (4.6mm $250 \mathrm{~mm}$ i.d., $5 \mathrm{~m}$ ). Solvents A (acetonitrile) and B (benzene) made up the mobile phase $(0.045$ percent $\mathrm{KH} 2 \mathrm{PO} 4$ ), where $0.8 \mathrm{mLmin}-1$ and $20 \mathrm{~mL}$ were the injection volume and flow rate, respectively. The mobile process was screened with a $0.45 \mathrm{~mm}$ filter and degassed under vacuum until application. The system was run at ambient temperature.

\subsection{Disc diffusion assay}

Briefly, a 0.5 McFarland scale $\left(1.510^{8}\right.$ colony forming units $\left.\left.(\mathrm{CFU}) / \mathrm{ml}\right)\right)$ bacteria culture was used in this experiment, with an optical density of $590 \mathrm{~nm}$. We applied this bacterial culture to nutrient agar with a sterile swab at this stage. Afterward, the blank discs were placed on the solid surface of nutrient agar while all of the discs were soaked in the GLME until saturated. Plates were placed within the incubator at $37^{\circ} \mathrm{C}$ for $18 \mathrm{~h}$, and finally, the diameter of inhibition zones was measured [17-19]. A solution containing 
$20 \%$ ethanol in water was used as control group because of probable presence of ethanol in final herbal extract.

\subsection{Minimum inhibitory concentrations (MICs) assay}

Both procedures in this assay were performed according to the Clinical and Laboratory Standards Institute's (CLSI) guidelines for determining GLME's antibacterial susceptibility [20-22]. The 96 well-plate was filled with $\mathrm{BHI}$ or liquid medium at a concentration of 90 liters for this experiment. The GLME methanolic extraction was then pumped into the culture medium at a concentration of $90 \mathrm{~L}$ (with a descending concentration from $1000 \mathrm{~g} / \mathrm{mL}$ to $7.8 \mathrm{~g} / \mathrm{mL})$. In the next step, $10 \mu \mathrm{L}$ of $600 \mathrm{~nm}$ OD (0.5 McFarland) microorganisms were transferred into the mentioned wells, which contained the developed samples. The plates were then incubated for 24 hours at $37^{\circ} \mathrm{C}$. We used Ampicillin as a standard drug to determine Ganoderma lucidum's antibacterial susceptibility in this method. A solution containing $20 \%$ ethanol in water was used as control group because of probable presence of ethanol in final herbal extract. The optical density was estimated at $600 \mathrm{~nm}$ in the final step (BioTek, Power WaveXS2). This process was carried out three times.

\subsection{Minimum bactericidal concentrations (MBCs) assay}

The value of MBCs was calculated by culturing the media from nutrient agar wells with no bacterial growth. A solution containing $20 \%$ ethanol in water was used as control group because of probable presence of ethanol in final herbal extract. The MBC value is the minor concentration capable of killing 98 percent of microorganisms in culture [23]. This procedure was also done three times.

\subsection{MTT assay}

MCF-7 and K562 cell lines were used to test the cytotoxicity of GLME. The positive control was hydrogen peroxide, and the negative control was the culture medium containing $20 \%$ ethanol was used as control group because of probable presence of ethanol in final herbal extract. A certain amount of each cell line (10000) was placed in each well containing DMEM culture media and incubated to achieve 85 to $90 \%$ confluence. The previous media was then used to substitute $100 \mu \mathrm{L}$ of GLME in a wide variety of concentrations. Then, in each well, $30 \mathrm{~mL}$ of MTT (3-(4,5 Dimethylthiazol-2-yl)-2,5-diphenyltetrazolium) stock solution (concentration $4 \mathrm{mg} / \mathrm{mL}$ ) was transferred and incubated under normal conditions. Purple formazan crystals formed due to the viable cells' mitochondrial function, and we used 100 liters of dimethyl sulfoxide (DMSO) to dissolve these crystals. The plate was shaken in a double orbital manner (for 5 minutes) to dissolve formazan crystals completely. Finally, the optical absorption of the mentioned solution was recorded at $540 \mathrm{~nm}$ using an Elisa plate reader (Model 50, Bio-Rad Corp, Hercules, California, USA) $[24,25]$. All tests were accomplished in triplicate [26]. The following equation describes the calculations of the cell viability:

$$
\% \text { Cellviability }=\frac{[O D(\text { cell }+ \text { compound })-O D(\text { compound })]}{[O D(\text { cell })-O D(\text { Culturemedia })]} * 100
$$

\subsection{Statistical analysis}


The statistical interpretations in this analysis were made using the Statistical Package of the Social Sciences (SPSS) 22 software (SPSS Inc., Chicago, IL, USA). The antibacterial and cytotoxic activities of GLME were compared using one-way ANOVA/Tukey experiments. After three trial replications, the significance amount was set at 0.05 .

\section{Results And Discussion 3.1. Characterization}

With a $\mathrm{KBr}$ tablet, FTIR analysis of GLME was performed in the $400-4000 \mathrm{~cm}^{-1}$ range (Bruker model Tensor II). A narrow band at $2919 \mathrm{~cm}^{-1}$, which was allocated to the $\mathrm{C}-\mathrm{H}$ stretching binding in aliphatic compounds, and $1981 \mathrm{~cm}^{-1}$ can confirm the presence of aromatic combination bands, while a peak at $3292 \mathrm{~cm}^{-1}$ can be attributed to the stretching bond of the hydroxyl functional groups $(-\mathrm{OH})$, as seen in Fig. 1a. For GLME, several transmittance bands in the regions of distinct amide bands suggest the presence of proteins [27]. The stretching frequency of $\mathrm{C}=0$ groups is associated with the amide-l band $\left(1634 \mathrm{~cm}^{-1}\right)$, while the bending vibration of $\mathrm{N}=\mathrm{H}$ groups is associated with the amide-ll band $\left(1538 \mathrm{~cm}^{-}\right.$ $\left.{ }^{1}\right)$. GLME had a critical characteristic band of $1035 \mathrm{~cm}^{-1}$, which was close to the stretching of the $\mathrm{C}-\mathrm{O}$ bond. This banding pattern can also be seen in other Chinese medicines, including Radix achyranthes, Cordyceps bidentatae, and Radix cyathulae [28]. According to Barker et al. [20], the $893 \mathrm{~cm}^{-1}$ band in the fingerprint area of $d$-glucopyranose is one of the most significant recorded bands. In sugar, this band is a $\mathrm{C}-\mathrm{H}$ bending vibration. The bending vibration of a saccharide group is represented by the bands at $554 \mathrm{~cm}^{-1}$ and $529 \mathrm{~cm}^{-1}$ [29].

The crystallinity of GLME was investigated using XRD, and the resulting pattern is shown in Fig. 1.b. The crystalline plane 002 was assigned to the XRD pattern, which showed an apparent plateau at around $2=$ $20^{\circ}$. No peaks existed at higher scattering angles, indicating that the compound was amorphous [30].

FE-SEM images at various scales (i.e., $1 \mathrm{~m}, 500 \mathrm{~nm}$, and $200 \mathrm{~nm}$ ) and EDAX analysis of GLME are shown in Fig. 2. GLME had a rod-shaped structure with particle sizes smaller than $60 \mathrm{~nm}$, as seen in Fig. 2. This natural commodity also contained a lot of carbon, nitrogen, oxygen, magnesium, sulfur, potassium, and calcium, according to EDAX research.

The contents of monosaccharides and disaccharides from GLME were calculated using an HPLC method in optimum separation conditions, with acetonitrile- 0.045 percent $\mathrm{KH} 2 \mathrm{PO} 4$ as the mobile step and a flow rate of $0.8 \mathrm{mLmin}-1$ at $250 \mathrm{~nm}$ as the detector. Polysaccharides from GLME were detected by comparing the retention time of each part with standard curves. Monosaccharides and disaccharides, such as lactose, glucose, sucrose, and maltose, were defined in Fig. 3C.

The inhibitory action of GLME against selected bacterial strains (i.e., Staphylococcus aureus, Enterococcus faecalis, E. coli, and Pseudomonas aeruginosa) was investigated using the microdilution method (Fig. 3a). GLME was reported to have antibacterial effects against microorganisms at high 
concentrations $(1000,500 \mathrm{~g} / \mathrm{ml})$. It can be noted that the antibacterial effects increased in a concentration-dependent manner as the concentration value increased. The obtained results revealed that the inhibitory effects of this product against gram-negative and gram-positive bacterial strains were not similar. According to the presented data in Table 1, it can be understood that this valuable product had higher antibacterial activity against $E$. coli and Pseudomonas aeruginosa. The MIC values of the GLME were $125 \mu \mathrm{g} / \mathrm{ml}$ and $250 \mu \mathrm{g} / \mathrm{ml}$ for Gram-negative and Gram-positive microorganisms, respectively. The viability of Staphylococcus aureus and Enterococcus faecalis subjected to GLME was 146 percent and 117 percent, respectively, at the most diluted concentration of the experiment $(7.8 \mathrm{~g} / \mathrm{mL})$, indicating that the extract had some beneficial effects on bacterial growth. GLME possesses bactericidal and bacteriostatic effects against Gram-negative and Gram-positive strains, mainly due to polysaccharide components in its structure. Figure 3 (d) shows a view of the disc diffusion method after exposure to four different microorganisms.

A common and acceptable approach for assessing cell viability is the MTT assay. This method can also detect and determine biomaterial toxicity [31-33]. MTT assay can depict the metabolism and mitochondrial activity of cells. This experiment evaluated the viability or proliferation of human breast and blood cancer cells after $24 \mathrm{~h}$ of treatment with methanolic extraction of GLME (see Fig. 3b). The metabolic performance of cells was changed in a dose-dependent manner by the GLME, where the dosage of the sample was varied from 1 to $3000 \mu \mathrm{g} / \mathrm{mL}$. By increasing the concentration from 1 to 3000 $\mu \mathrm{g} / \mathrm{ml}$, the cell viability percentage was diminished from $108-2.5 \%$ for the $\mathrm{K}-562$ blood cancer cell line and $91-6 \%$ for the MCF-7 cancerous breast cell line. The IC50 values of 0.5 and $0.75 \mathrm{mg} / \mathrm{mL}$ were obtained for MCF-7 and K-562 cancer cell lines, which confirmed the higher anticancer activity of the GLME against breast cancer cells compared to blood cancer cells.

Table 1

Performance of the GLME against selected microorganisms.

\begin{tabular}{|c|c|c|c|}
\hline \multirow[t]{3}{*}{ Microorganisms } & \multicolumn{3}{|l|}{ Antibacterial tests } \\
\hline & Zone of inhibition & MIC & MBC \\
\hline & $(\mathrm{mm},($ Mean $\pm \mathrm{SD})$ & $(\mu \mathrm{g} / \mathrm{ml})$ & $(\mu \mathrm{g} / \mathrm{ml})$ \\
\hline E.coli & $44 \pm 0.09$ & 125 & 125 \\
\hline Pseudomonas aeruginosa & $36 \pm 0.1$ & 125 & $>125$ \\
\hline Staphyloccus aureus & $28 \pm 0.07$ & 250 & 250 \\
\hline Enterococcus faecalis & $34 \pm 0.2$ & 250 & $>250$ \\
\hline
\end{tabular}




\section{Conclusions}

GLME is known to be quite a competent medicinal and nutraceutical agent, owing to its pharmacological, chemical components derived from fruit bodies, mycelium, and spores, which can be health-promoting agents. This work is motivated by research studies looking for pharmacological products to address chronic and acute diseases, where further resources and studies are required to explore such products' adverse effects and toxicity. More clinical studies are needed to validate the efficacy and protection provided by such products. More experiments and clinical research in the future are likely to take place on a wide scale. This research aims to examine the antimicrobial, cytotoxic, and genotoxic activity of the GLME. The extract was evaluated for its antibacterial and antifungal efficacy toward different microorganisms by utilizing a microdilution broth system. GLME was examined using an approach to assess its cytotoxic activity against breast cancer and blood cancer cells.

\section{Abbreviations}

XRD: X-ray Diffraction

FE-SEM: Field Emission Scanning Electron Microscopy

TEM: Transmission Electron Microscopy

AFM: Atomic Force Microscopy

FTIR: Fourier-Transform Infrared Spectroscopy

UV: Ultraviolet light

HPLC: High-Performance Liquid Chromatography

GL: Ganoderma lucidum

GLME: Ganoderma lucidum methanolic extract

MIC: Minimum Inhibitory Concentrations

MBC: Minimum Bactericidal Concentrations

EDAX: Energy Dispersive Spectroscopy

CFU: colony forming units

CLSI: Clinical and Laboratory Standards Institute

DMEM: Dulbecco's Modified Eagle Medium 
OD: Optical Density

MTT: (3-(4,5 Dimethylthiazol-2-yl)-2,5-diphenyltetrazolium)

DMSO: Dimethyl Sulfoxide

\section{Declarations}

\section{Ethics approval and consent to participate}

Not applicable

\section{Consent for publication}

Not applicable

\section{Availability of data and materials}

All data generated or analyzed during this study are included in this published article

\section{Competing interests}

The authors declare that they have no competing interests

\section{Funding}

There is no funding for this study.

\section{Authors' contributions}

SMM and AG developed the idea and structure of the review article. SMM, VRN, SAH and KY wrote the manuscript collecting the materials from databases. MS, AG, W-HC and NO revised and improved the manuscript. AG and NO supervised the manuscript. All the authors have given approval to the final version of the manuscript.

\section{Acknowledgements}

Not applicable

\section{References}

1. Nabavizadeh M, Abbaszadegan A, Gholami A, Sheikhiani R, Shokouhi M, Shams MS, Ghasemi Y: Chemical constituent and antimicrobial effect of essential oil from Myrtus communis leaves on microorganisms involved in persistent endodontic infection compared to two common endodontic irrigants: An in vitro study. Journal of conservative dentistry: JCD 2014, 17(5):449. 
2. Omidifar N, Nili-Ahmadabadi A, Gholami A, Dastan D, Ahmadimoghaddam D, Nili-Ahmadabadi H: Biochemical and Histological Evidence on the Protective Effects of $<i>$ Allium hirtifolium Boiss (Persian Shallot) as an Herbal Supplement in Cadmium-Induced Hepatotoxicity. Evidence-Based Complementary and Alternative Medicine 2020, 2020:7457504.

3. Abbaszadegan A, Gholami A, Ghahramani Y, Ghareghan R, Ghareghan M, Kazemi A, Iraji A, Ghasemi $\mathrm{Y}$ : Antimicrobial and cytotoxic activity of Cuminum cyminum as an intracanal medicament compared to chlorhexidine gel. Iranian endodontic journal 2016, 11(1):44.

4. Omidifar N, Nili-Ahmadabadi A, Nakhostin-Ansari A, Lankarani KB, Moghadami M, Mousavi SM, Hashemi SA, Gholami A, Shokripour M, Ebrahimi Z: The modulatory potential of herbal antioxidants against oxidative stress and heavy metal pollution: plants against environmental oxidative stress. Environmental Science and Pollution Research 2021, 28(44):61908-61918.

5. Ahmad MF: Ganoderma lucidum: Persuasive biologically active constituents and their health endorsement. Biomedicine \& Pharmacotherapy 2018, 107:507-519.

6. Sobowale MT, Ozolua RI, Uwaya DO, Ayinde BA: Effects of Concurrently Administered Aqueous Extract of Lingzhi or Reishi Medicinal Mushroom, Ganoderma lucidum (Agaricomycetes), and Lead Acetate in Rats. International Journal of Medicinal Mushrooms 2019, 21(2).

7. Omidifar N, moghadami M, Mousavi SM, Hashemi SA, Gholami A, Shokripour M, Sohrabi Z: Trends in Natural Nutrients for Oxidative Stress and Cell Senescence. Oxidative Medicine and Cellular Longevity 2021, 2021:7501424.

8. Ahmad MF: Ganoderma lucidum: A Macro Fungus with Phytochemicals and Their Pharmacological Properties. In: Plant and Human Health, Volume 2. edn.: Springer; 2019: 491-515.

9. Zhao X, Zhou D, Liu Y, Li C, Zhao X, Li Y, Li W: Ganoderma lucidum polysaccharide inhibits prostate cancer cell migration via the protein arginine methyltransferase 6 signaling pathway. Molecular medicine reports $2018,17(1): 147-157$.

10. Zolj S, Smith MP, Goines JC, T'Shura SA, Huff MO, Robinson DL, Lau JM: Antiproliferative effects of a triterpeneenriched extract from lingzhi or reishi medicinal mushroom, ganoderma lucidum (agaricomycetes), on human lung cancer cells. International journal of medicinal mushrooms 2018, 20(12).

11. Bai Jh, Xu J, Zhao J, Zhang R: Ganoderma lucidum Polysaccharide Enzymatic Hydrolysate Suppresses the Growth of Human Colon Cancer Cells via Inducing Apoptosis. Cell Transplantation 2020, 29:0963689720931435.

12. Jin H, Song C, Zhao Z, Zhou G: Ganoderma Lucidum Polysaccharide, an Extract from Ganoderma Lucidum, Exerts Suppressive Effect on Cervical Cancer Cell Malignancy through Mitigating EpithelialMesenchymal and JAK/STAT5 Signaling Pathway. Pharmacology 2020:1-10.

13. Wu Y-L, Han F, Luan S-S, Ai R, Zhang P, Li H, Chen L-X: Triterpenoids from Ganoderma lucidum and their potential anti-inflammatory effects. Journal of agricultural and food chemistry 2019 , 67(18):5147-5158. 
14. Huang $\mathrm{C}-\mathrm{H}$, Lin W-K, Chang SH, Tsai G-J: Evaluation of the hypoglycaemic and antioxidant effects of submerged Ganoderma lucidum cultures in type 2 diabetic rats. Mycology 2020:1-12.

15. Rahman MA, Abdullah N, Aminudin N: Evaluation of the antioxidative and hypo-cholesterolemic effects of lingzhi or reishi medicinal mushroom, Ganoderma lucidum (Agaricomycetes), in ameliorating cardiovascular disease. International journal of medicinal mushrooms 2018, 20(10).

16. Zeng X, Li P, Chen X, Kang Y, Xie Y, Li X, Xie T, Zhang Y: Effects of deproteinization methods on primary structure and antioxidant activity of Ganoderma lucidum polysaccharides. International journal of biological macromolecules 2019, 126:867-876.

17. Gholami A, Shahin S, Mohkam M, Nezafat N, Ghasemi Y: Cloning, characterization and bioinformatics analysis of novel cytosine deaminase from Escherichia coli AGH09. International Journal of Peptide Research and Therapeutics 2015, 21(3):365-374.

18. Abbaszadegan A, Ghahramani Y, Gholami A, Hemmateenejad B, Dorostkar S, Nabavizadeh M, Sharghi $\mathrm{H}$ : The effect of charge at the surface of silver nanoparticles on antimicrobial activity against gram-positive and gram-negative bacteria: a preliminary study. Journal of Nanomaterials 2015, 2015.

19. Gholami A, Rasoul-Amini S, Ebrahiminezhad A, Abootalebi N, Niroumand U, Ebrahimi N, Ghasemi Y: Magnetic properties and antimicrobial effect of amino and lipoamino acid coated iron oxide nanoparticles. Minerva Biotecnologica 2016, 28(4):177-186.

20. Gholami A, Mohammadi F, Ghasemi Y, Omidifar N, Ebrahiminezhad A: Antibacterial activity of SPIONs versus ferrous and ferric ions under aerobic and anaerobic conditions: a preliminary mechanism study. IET Nanobiotechnol 2020, 14(2):155-160.

21. Gholami A, Ebrahiminezhad A, Abootalebi N, Ghasemi Y: Synergistic evaluation of functionalized magnetic nanoparticles and antibiotics against Staphylococcus aureus and Escherichia coli. Pharmaceutical nanotechnology 2018, 6(4):276-286.

22. Zargarnezhad S, Gholami A, Khoshneviszadeh M, Abootalebi SN, Ghasemi Y: Antimicrobial activity of isoniazid in conjugation with surface-modified magnetic nanoparticles against Mycobacterium tuberculosis and nonmycobacterial microorganisms. Journal of Nanomaterials 2020, 2020.

23. Abootalebi SN, Mousavi SM, Hashemi SA, Shorafa E, Omidifar N, Gholami A: Antibacterial Effects of Green-Synthesized Silver Nanoparticles Using Ferula asafoetida against Acinetobacter baumannii Isolated from the Hospital Environment and Assessment of Their Cytotoxicity on the Human Cell Lines. Journal of Nanomaterials 2021, 2021.

24. Gholami A, Emadi F, Nazem M, Aghayi R, Khalvati B, Amini A, Ghasemi Y: Expression of key apoptotic genes in hepatocellular carcinoma cell line treated with etoposide-loaded graphene oxide. Journal of Drug Delivery Science and Technology 2020, 57:101725.

25. Gholami A, Emadi F, Amini A, Shokripour M, Chashmpoosh M, Omidifar N: Functionalization of Graphene Oxide Nanosheets Can Reduce Their Cytotoxicity to Dental Pulp Stem Cells. Journal of Nanomaterials 2020, 2020:6942707. 
26. Mousavi SM, Hashemi SA, Zarei M, Bahrani S, Savardashtaki A, Esmaeili H, Lai CW, Mazraedoost S, Abassi M, Ramavandi B: Data on cytotoxic and antibacterial activity of synthesized Fe304 nanoparticles using Malva sylvestris. Data in brief 2020, 28:104929.

27. Choong YK, Sun S-Q, Zhou Q, Ismail Z, Rashid BAA, Tao J-X: Determination of storage stability of the crude extracts of Ganoderma lucidum using FTIR and 2D-IR spectroscopy. Vibrational Spectroscopy 2011, 57(1):87-96.

28. Jiang Y, David B, Tu P, Barbin Y: Recent analytical approaches in quality control of traditional Chinese medicines-a review. Analytica chimica acta 2010, 657(1):9-18.

29. Barker $S$, Bourne $E$, Whiffen $D$ : Use of infrared analysis in the determination of carbohydrate structure. Methods of biochemical analysis 1956, 3:213.

30. Papaioannou N, Marinovic A, Yoshizawa N, Goode AE, Fay M, Khlobystov A, Titirici M-M, Sapelkin A: Structure and solvents effects on the optical properties of sugar-derived carbon nanodots. Scientific Reports 2018, 8(1):6559.

31. Yousefi K, Manesh HD, Khalifeh AR, Gholami A: Fabrication and Characterization of a Nanofast Cement for Dental Restorations. BioMed Research International 2021, 2021:7343147.

32. Mousavi SM, Hashemi SA, Gholami A, Omidifar N, Zarei M, Bahrani S, Yousefi K, Chiang W-H, Babapoor A: Bioinorganic Synthesis of Polyrhodanine Stabilized Fe $<$ sub $>3</$ sub $>0<$ sub $>$ 4</sub>/Graphene Oxide in Microbial Supernatant Media for Anticancer and Antibacterial Applications. Bioinorganic Chemistry and Applications 2021, 2021:9972664.

33. Gholami A, Shams MS, Abbaszadegan A, Nabavizadeh M: Ionic liquids as capping agents of silver nanoparticles. Part Il: Antimicrobial and cytotoxic study. Green Processing and Synthesis 2021, 10(1):585-593.

\section{Figures}



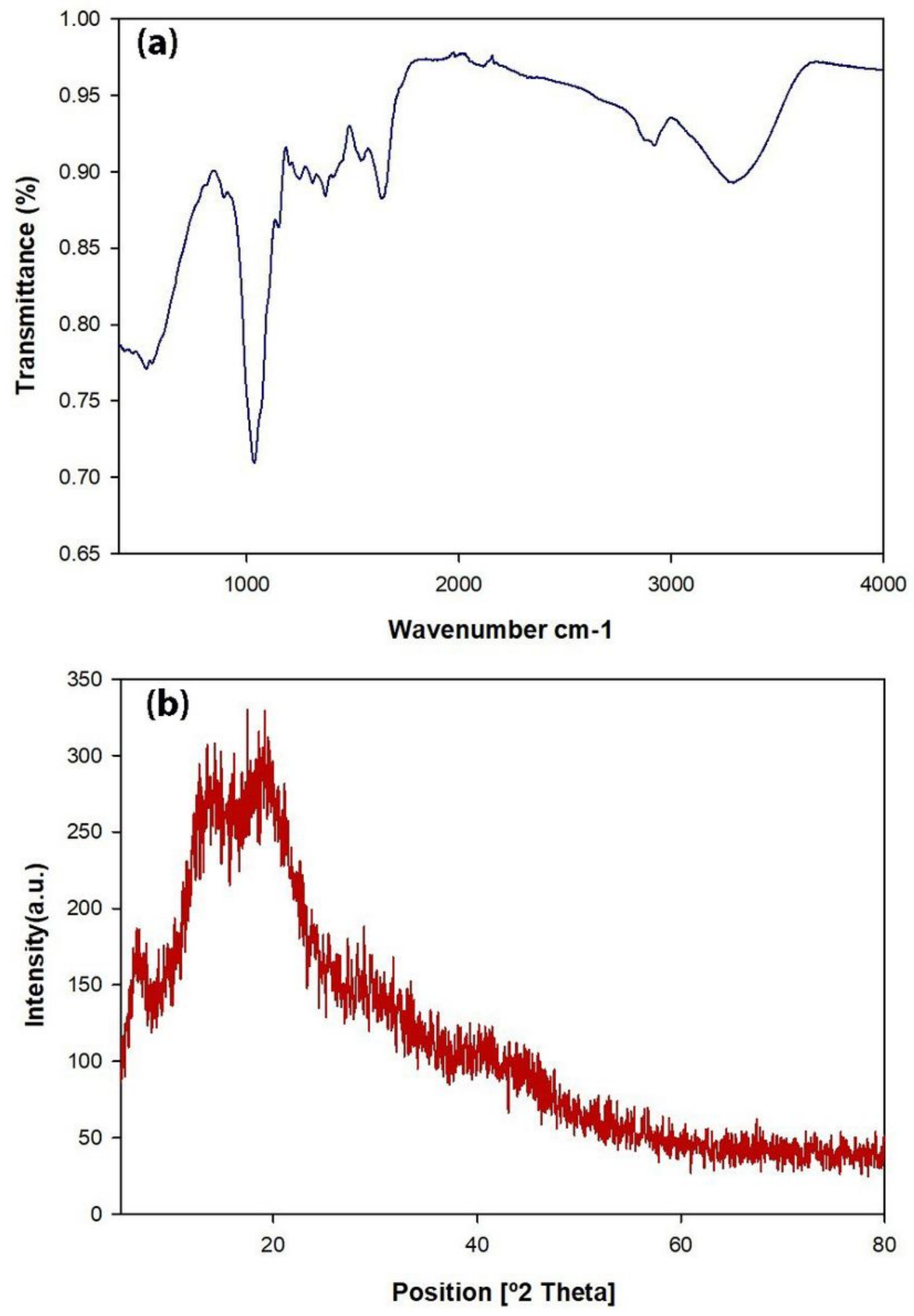

Figure 1

a) FTIR spectrum and b) XRD pattern of GLME 

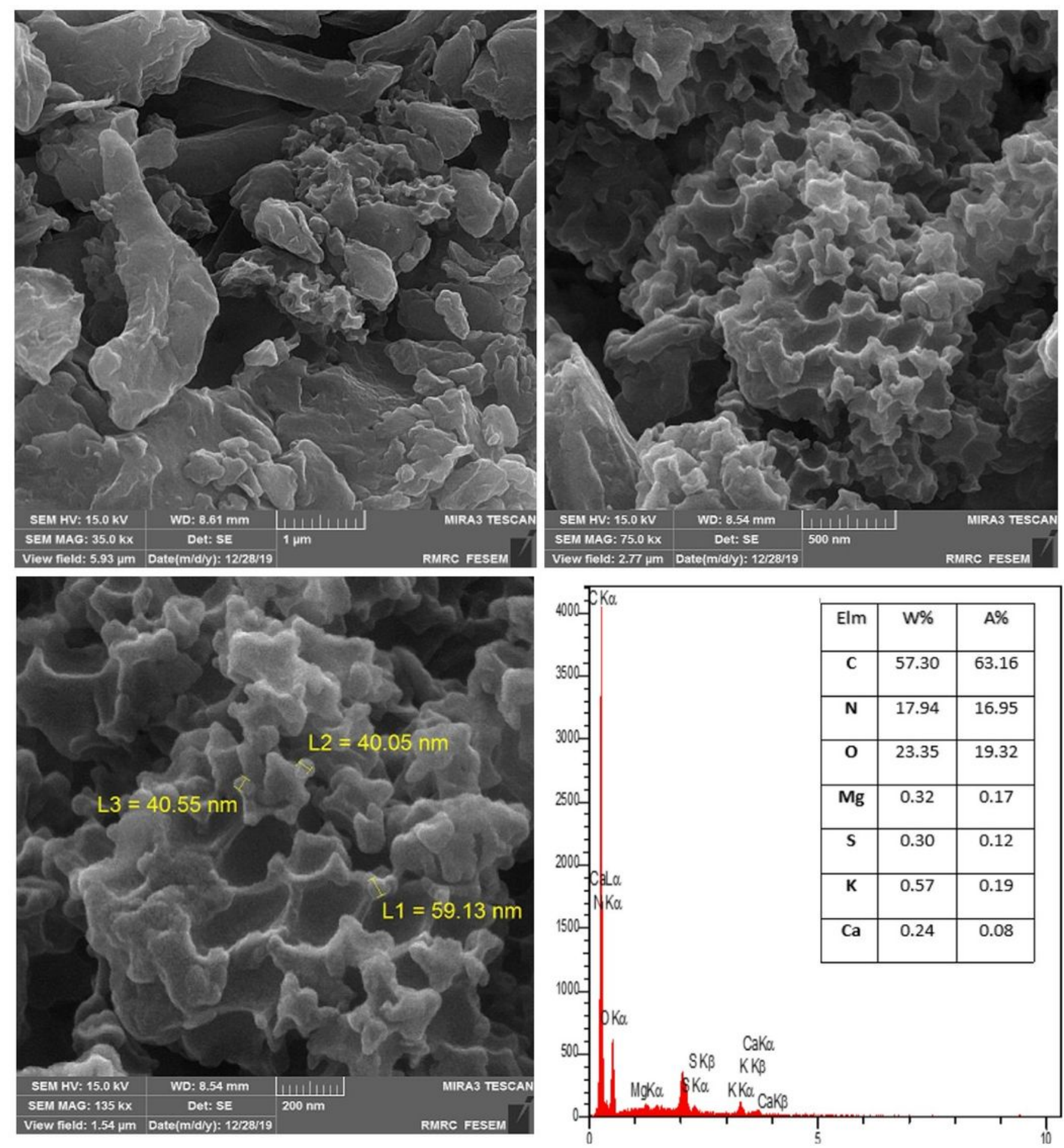

Figure 2

The natural product's FESEM images and EDAX analysis 
(a)
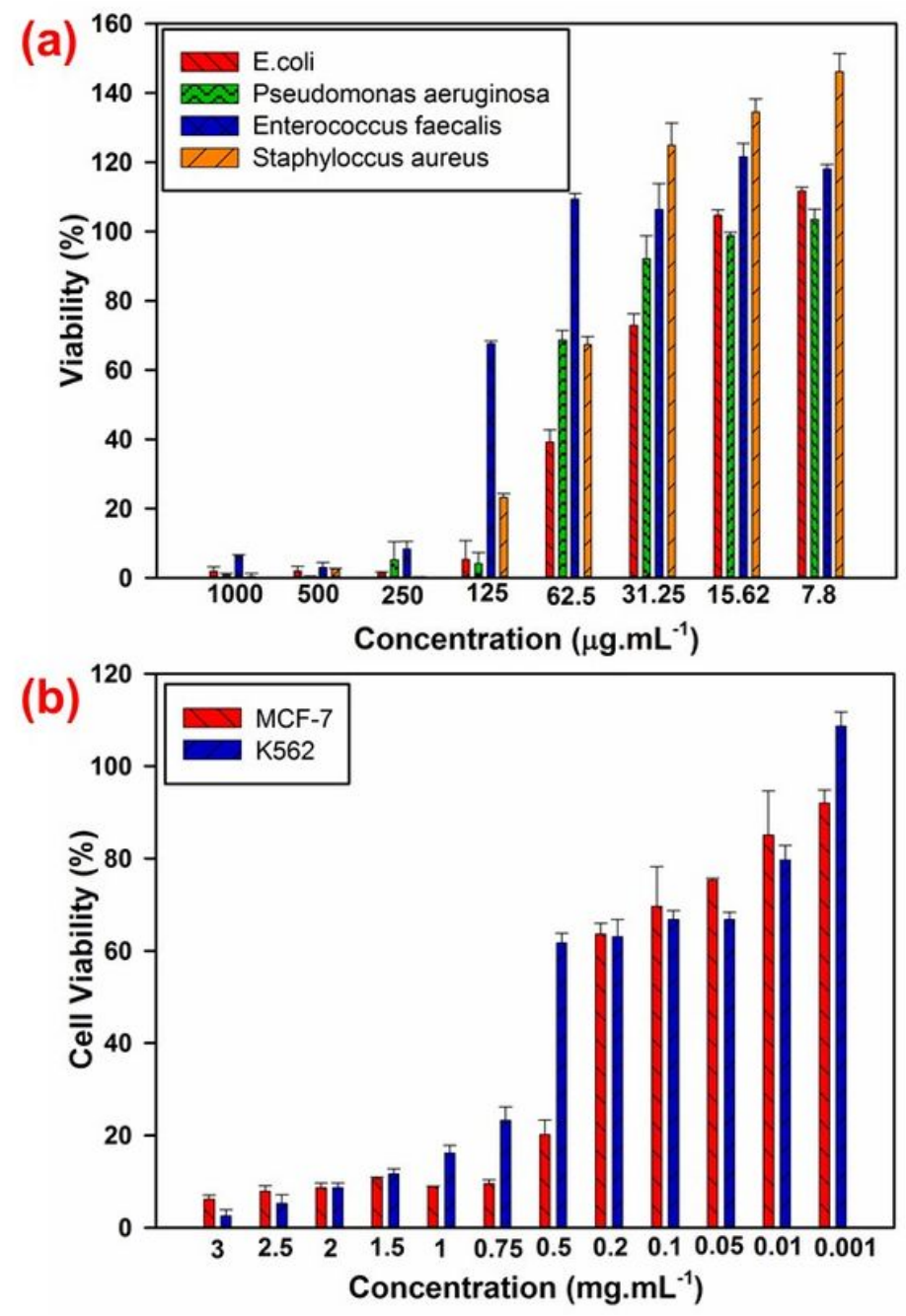

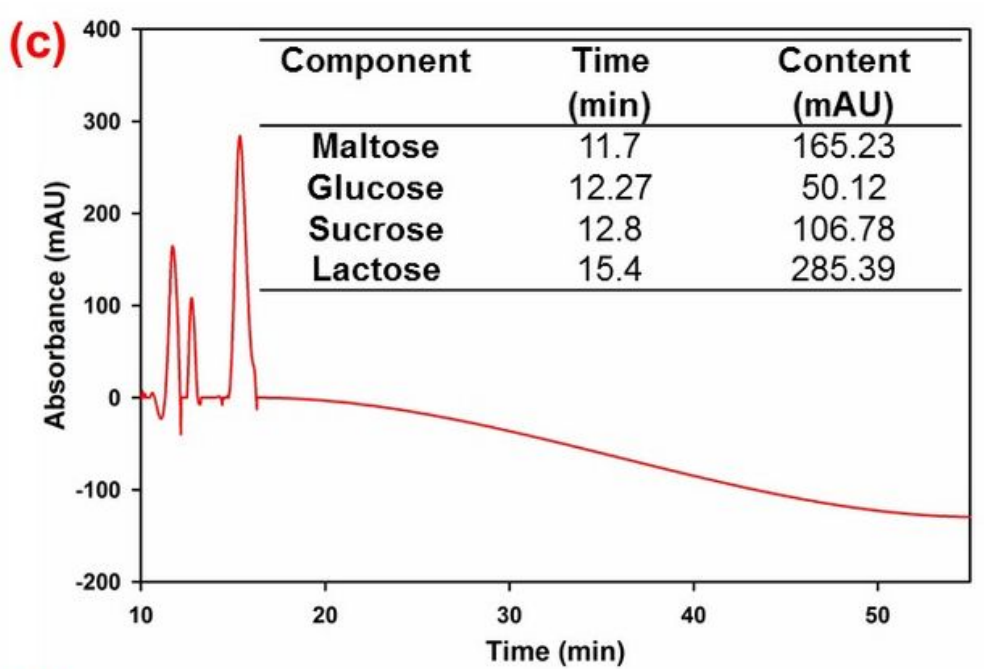

(d)
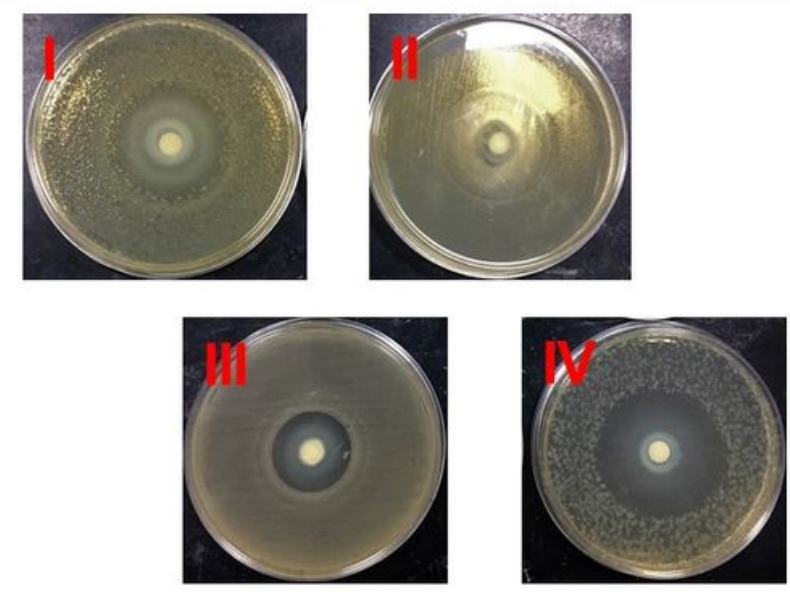

Figure 3

(a) Effects of methanolic GLME extraction on various microorganism's viability percentages in different concentrations (each bar reflects the mean SD (standard deviation) of three independent tests). b) effects of methanolic GLME extraction on human breast and blood cancer cells. GLME blocked cell growth in MCF-7 and K-562 cell lines, as shown by the MTT assay, in which cells were treated with various concentrations of GLME for 24 hours. The results are interpreted by finding the mean and standard deviation of the three separate experiments. (c) HPLC analysis of the GLME. (d) Inhibition zone of GLME against (I) Pseudomonas aeruginosa, (II) Enterococcus faecalis, (III) Staphylococcus aureus, and (IV) Escherichia coli. 